AperTO - Archivio Istituzionale Open Access dell'Università di Torino

Anti-prothrombin (aPT) and anti-phosphatidylserine/prothrombin (aPS/PT) antibodies and the risk of thrombosis in the antiphospholipid syndrome. A systematic review.

This is a pre print version of the following article:

Original Citation:

Availability:

This version is available http://hdl.handle.net/2318/142598

since 2016-10-20T16:43:06Z

Published version:

DOI:10.1160/TH13-06-0509

Terms of use:

Open Access

Anyone can freely access the full text of works made available as "Open Access". Works made available under a Creative Commons license can be used according to the terms and conditions of said license. Use of all other works requires consent of the right holder (author or publisher) if not exempted from copyright protection by the applicable law. 
This is the author's final version of the contribution published as:

Sciascia S;Sanna G;Murru V;Roccatello D;Khamashta MA;Bertolaccini ML. Anti-prothrombin (aPT) and anti-phosphatidylserine/prothrombin (aPS/PT) antibodies and the risk of thrombosis in the antiphospholipid syndrome. A systematic review.. THROMBOSIS AND HAEMOSTASIS. 111 (2) pp: 354-364.

DOI: 10.1160/TH13-06-0509

The publisher's version is available at:

http://www.schattauer.de/index.php?id=5236\&mid=20459\&L=1

When citing, please refer to the published version.

Link to this full text:

http://hdl.handle.net/2318/142598 


\title{
Anti-prothrombin (aPT) and anti phosphatidylserine/prothrombin (aPS/PT) antibodies and the risk of thrombosis in the antiphospholipid syndrome
} A systematic review

\author{
Savino Sciascia ${ }^{1,2}$; Giovanni Sanna ${ }^{3}$; Veronica Murru ${ }^{1}$ Dario Roccatello²; Munther A. Khamashta ${ }^{1,3}$; Maria Laura \\ Bertolaccini $^{1}$ \\ ${ }^{1}$ Graham Hughes Lupus Research Laboratory, Lupus Research Unit, The Rayne Institute, Division of Women's Health, King's \\ College London, ${ }^{2}$ Centro di Ricerche di Immunologia Clinica ed Immunopatologia e Documentazione su Malattie Rare \\ (CMID), Università di Torino, Italy; ${ }^{3}$ Louise Coote Lupus Unit, Guy's and St Thomas' NHS Foundation Trust, \\ St Thomas' Hospital, London, UK
}

Abstract:

Background: Antibodies to prothrombin are detected by directly coating prothrombin on irradiated ELISA plates (aPT) or by using the phosphatidylserine/prothrombin complex as antigen (aPS/PT). Although these antibodies have both been associated with antiphospholipid syndrome (APS) and a correlation between the two assays have been reported, it seems that aPT and aPS/PTbelong to different populations of autoantibodies. Objectives: To systematically review the available evidence on aPT and aPS/PT antibodies and the risk of thrombosis in APS. Methods: Medline-reports published between 1988 and 2013 investigating aPT and aPS/PT as a risk factor for thrombosis were included. Whenever possible, antibody isotype(s) and site of thrombosis were analysed. Results: This systematic review is based on available data from more than 7000 patients and controls from 38 studies analyzing aPT and 10 aPS/PT. Antibodies to prothrombin (both aPT and aPS/PT) increased the risk thrombosis (OR 2.3 [95\% Cl 1.72-3.5]). aPS/PT seemed to represent a stronger risk factor for thrombosis, both arterial and/or venous than aPT (OR 5.11 [95\% Cl 4.2-6.3] and 1.82 [95\% $\mathrm{Cl} 1.44-2.75]$, respectively). Conclusion: Routine measurement of aPS/PT (but not aPT) might be useful in establishing the thrombotic risk of patients with previous thrombosis and/or systemic lupus erythematosus. Their inclusion as laboratory criteria for the APS should be indisputably further explored.

INTRODUCTION: Antiphospholipid antibodies (aPL) are a wide and heterogeneous family of immunoglobulin G, M and, less frequently $A$, initially thought to target negatively charged phospholipids (1). $2 \mathrm{GPI}$ ) and the lupus $\beta 2$ glycoprotein-I (anti- $\beta A$ lthough anticardiolipin ( $\mathrm{aCL}$ ), anti- anticoagulant (LA) are the routinely tested antibodies for the diagnosis of antiphospholipid syndrome (APS) (2), research on aPL is continuously expanding in the search for new clinically useful markers. Prothrombin, a plasma protein, was described as a cofactor for a 'circulating anticoagulant' by Loeliger in 1959 (3). Prothrombin is a common antigenic target for aPL, reported in around 50$90 \%$ of patients with other aPL (4). Because antiprothrombin antibodies have heterogeneous immunologic and functional properties, their clinical significance is still under debate. Evidence of pathogenicity comes from animal model. Active immunization with prothrombin was associated with prothrombotic activity of blood in an ex-vivo mice model, producing direct evidence for thrombus induction by antibodies to prothrombin (5). Antibodies to prothrombin are usually detected by two different system assays, by directly coating prothrombin on irradiated ELISA plates (aPT) or by using the phosphatidylserine/prothrombin complex as antigen (aPS/PT). Although aPT and/or aPS/PT have both been associated with APS and a correlation between the two assays have been reported (6), it seems that aPT and aPS/PT belong to different populations of autoantibodies even though they can both be present in the same patient (7).

Studies on the significance of antiprothrombin antibodies in thrombosis, including a systematic review (8) have shown controversial results. Therefore the value of antiprothrombin antibodies as markers of APS remains to be determined whilst the strength of the association of anti-prothrombin antibodies, detected either as aPT or aPS/PT, with thrombosis remains to be established. To contribute to this issue, we carried out a systematic review 
of the literature. In an attempt to summarise all available data on this subject, we selected papers whose design allowed us to objectively verify the clinical events and to establish the odds ratio with their $95 \%$ confidence interval (OR $[95 \% \mathrm{Cl}])$ for aPT and/or aPS/PT for thrombosis. Whenever possible, the antibody isotype(s) and the site of thrombosis were taken into account.

\section{Patients, materials, and methods}

\section{Literature search and selection of studies}

Articles were identified by a computer-assisted search of the literature. The search strategy was applied to Ovid MEDLINE (R) In Process \& other non-indexed citations and Ovid MEDLINE from 1988 through 2013. The grey literature was searched by applying a similar strategy to Google ScholarR , PubMedR and the Proquest Dissertation \& Theses databases. Additional references were identified from manual review of the reference lists of included articles. A schematic representation of the search strategy, key words and subject terms used in the search is given in Figure 1 . This approach has been previously reported and validated $(8,9)$. The search was further refined using the following limitations: "English language" and "human." Review articles were excluded from the search. For aPT and aPS/PT we mainly focused on studies that met specific requirements such as specification of the temporal sequence between measurement of the antibodies and the events, or the presence of a control group besides the objective documentation of thrombosis. Prospective, crosssectional, case-control, and ambispective studies met these criteria, although retrospective studies were also included. All series of 7 or more patients were classified according to the aPL type and the underlying disease, and information about the study design and the assay methods was recorded.

\section{Assessment of validity}

\section{Study Selection}

Potential studies identified with the above search strategy were exported to an electronic reference management software program (RefWorks v.2.0). Duplicate studies were identified and removed using the filter functions "exact duplicates" and "close duplicates." Two independent reviewers (SS, MLB) reviewed all potential studies. Eligibility was first determined by review of the title and abstract and then by full article review. Disagreements were resolved by consensus; if consensus could not be achieved, a third party (GS) would provide an assessment of eligibility. As the data on eligibility were dichotomous (eligible: yes / no), inter-rater agreement at both the title and abstract review and the full article review stages was determined by calculation of Cohen's kappa coefficient (10). The patient population and laboratory methods were systematically esamine.

Patient population: We noted whether eligibility criteria and confounding factors were specified for patients and, when included, controls. Patients were classified according to their underlying disease or syndrome. The major categories included systemic lupus erythematosus (SLE), other autoimmune diseases, non autoimmune diseases, arterial thrombosis, venous thrombosis and aPL positivity.

Assay methods: Only studies that objectively verified the thromboembolic events were included. The following methods were considered: computerized ultrasonography or venography for deep vein thrombosis; radionuclide lung scanning or angiography for pulmonary embolism; arteriography for peripheral arterial occlusions; computed tomography, resonance imaging, or angiography for ischemic stroke; and electrocardiogram and cardiac enzymes for myocardial infarction. Among the details of thrombosis, we noted the site (arterial or venous) and whether it was the first episode or a recurrence. Only studies that objectively described the methodological approach for aPT and/or aPS/PT were included. We registered the aPT and aPS/PT antibody isotype (s) and how normal cut off was expressed (i.e. the number of standard deviations above the mean of controls, the multiple of the mean, the 
percentile, or quartile) (data not shown). In view of the current lack of standardization for these assays, the decision to include or exclude a study did not take into account the method used to detect aPL, as long as the determination of the cut-off values was fully detailed. Articles were then analyzed both pooled together and separately, according to the methods used for anti-prothrombin antibodies testing (i.e. aPT or aPS/PT).

\section{Statistical analysis}

Odds ratios with $95 \% \mathrm{Cl}(\mathrm{OR}[95 \% \mathrm{CI}])$ for arterial and/or venous thrombosis were recorded. If not available, they were calculated, whenever possible, by means of contingency tables. In case-control and cross-sectional studies, contingency tables were used to compare the proportion of aPT and/or aPS/PT in patients with and without thrombosis. In prospective studies, contingency tables were established as previously reported $(8,9)$. Briefly, if SLE was the enrolment criterion, the OR $[95 \% \mathrm{Cl}]$ was calculated by comparing the proportion of aPT and/or aPS/PT antibodies in patients who did or did not develop thrombosis during followup. If thrombosis was the enrolment criterion, the OR $[95 \% \mathrm{Cl}]$ was calculated by comparing the proportion of aPT and/or aPS/PT in patients with or without recurrent thrombosis during follow up. If positivity for aPL was the enrolment criterion, the OR $[95 \% \mathrm{Cl}]$ was calculated by comparing the rates of thrombosis during follow-up of patients grouped according to different antibody types and titers.

\section{Risk of Bias Assessment}

One reviewer (SS) assessed the risk of bias of individual studies using the Newcastle-Ottawa Scale (NOS) for cohort studies, and the NOS for case control studies. The NOS is a scoring tool used to assess quality of evidence and risk of bias for non-randomized studies included in meta-analyses(11) The overall quality of evidence was determined using GRADE criterion and summarized using GRADE profiler (12).

\section{Results Literature search strategy and articles retrieved}

Sixty-six articles were retrieved: 48 investigated aPT $(6,7,13-59)$ and 18 dealt with aPS/PT $(6,7,24,39,43,44,52$, $57,58,60-68)$ (Figure 1). Of them, 7 studies $(6,7,24,39,42,43,64)$ analyzed both aPT and aPS/PT. After full article review, 48 publications met the eligibility criteria for inclusion in the review (kappa 0.94). Two further publications $(69,70)$ were obtained from review of the reference lists of included articles; however they were excluded because it was not possible to differentiate APS patients with thrombosis from those with pregnancy morbidity. No further publications were obtained from review of the grey literature. The majority of the excluded articles for the following reasons: in 8 papers $(49,51,61-65,68)$, the OR $[95 \% \mathrm{Cl}]$ for thrombosis was not provided and could not be calculated; 10 other studies $(47,48,50,53-59)$ were found not pertinent for the purpose of this review. The main characteristics of the remaining 48 articles are depicted in Tables 1 and 2. Overall, these studies provided information on 6006 patients and 1422 controls. Four prospective studies contributed with 417 patients. As most of the available studies were retrospective, we failed to separately analyze them on the basis of their design. In some studies healthy controls were involved only in the setting up of cut off values for aPT and/or aPS/PT testing. Indeed, they were reported but not 2GPI were the $\beta$ included in the analysis. SLE, APS, and the presence of $\mathrm{LA}, \mathrm{aCL}$ and/or anti- enrolment criteria in 37 studies. Only 16 studies performed multivariate analysis using logistic regression, allowing a risk assessment analysing the joint contribution of each risk factor.

\section{Studies on aPT}

The OR with $95 \% \mathrm{Cl}$ of aPT for thrombosis were calculated in 38 studies on 5705 patients and 1262 controls (Table 1, Figure 3). One study (42) used 2 methods to detect the antibodies and, therefore, results are reported for both of the assays. Overall, 22 (49\%) of 45 associations reached significance: 2 of 7 associations with arterial thrombosis, 7 of 11 with venous thrombosis, and 13 of 27 with any thrombosis (as no distinction was possible 
between venous and arterial thrombosis). In one case, the association was confirmed after multivariate analysis only if associated to positive LA (26). Isotype analysis was performed in a few studies. These showed that IgG aPT were significantly associated with thrombosis as a whole in 6 out of 7 studies $(86 \%)(6,7,31,34,38,44,46)$ and with venous thrombosis in 3 of 5 studies $(60 \%)(6,27,43,44,71)$. No associations between IgG aPT with arterial thrombosis were reported $(6,42,44,71)$. IgM aPT was associated with thrombosis as a whole in $3(42 \%)$ of 7 studies $(6,7,31,34,38,44,46)$. However, no associations were sustained after subgrouping between $\mathrm{h}$ arterial $(6,42,44,71)$ or venous thrombosis $(6,27,43,44,71)$. Studies that included multivariate analysis are shown in Table 1. Overall, IgG aPT seemed more consistently associated with thrombosis than IgM antibodies. The lack of reference materials to quantify aPT meant we could not assess whether the risk correlated with their titers.

\section{Studies on aPS/PT}

The OR [95\% $\mathrm{Cl}$ ] of aPS/PT for thrombosis were available in 10 studies on 1775 patients and 628 controls (Table 2; Figure 4). Overall, 15 out of 18 analyses ( $83 \%$ ) reported significant associations: 3 out of 6 with arterial thrombosis, 4 out of 4 with venous thrombosis, and 8 out of 8 with thrombosis as a whole. Isotype analysis showed that IgG aPS/PT was associated with thrombosis as a whole, particularly with venous thrombosis in all the studies. Three studies failed to confirm the association between IgG aPS/PT and arterial thrombosis $(39,55,62)$. The IgM isotype reached significance with thrombosis as a whole in all the studies but one (44). When analysed separately, the association with venous thrombosis was confirmed in all the studies, while the association with arterial events was confirmed in 2 studies $(66,67)$ out of 4 (Figure 4). Five studies $(24,52,60,66,67)$ performed multivariate analysis. The association between aPS/PT and thrombosis as a whole and venous thrombosis was confirmed in all. In two studies, a significant association with arterial thrombosis was lost after multivariate analysis $(37,67)$.

\section{Comparison of aPT and aPS/PT}

There were 7 studies $(6,7,24,39,42,43,64)$ that directly compared aPT and aPS/PT and their OR for thrombosis in 1196 Patients. When analysed within the same studies, aPS/PT is shown to be more strongly associated with thrombosis, both arterial and venous, than aPT. Overall, 10 out of 11 (90\%) possible analyses derived from the 7 studies reported a significant association between any thrombosis and aPS/PT compared to 5/11 for aPT. Analysis in relation to the type of thrombosis showed that aPS/PT only seemed to be associated with arterial events. The association with venous thrombosis was confirmed in all the studies for between aPS/PT and in 4 out 6 for aPT.

\section{DISCUSSION}

This systematic review of the literature aimed at establishing the strength of the association between antiprothrombin antibodies, tested either as aPT and/or aPS/PT, with thrombosis. Data on more than 7000 patients and controls from 38 studies analyzing aPT and 10 aPS/PT were available for our systematic review. Although 10 studies measured aPS/PT, only 7 directly compared the odds ratio for thrombosis in about a thousand patients and controls. The aPS/PT antibodies were more significantly associated with thrombosis. Although indirect and potentially risky, comparison of the studies that analyzed only one antibody confirmed this increasing awareness. Overall, this review formally establishes aPS/PT are strong risk factors for thrombosis, irrespective of the site and type of thrombosis. aPS/PT have an odds ratio for thrombosis three to eighteen times higher than controls $(6,7$, $24,39,43,44,52,57,58,60-68)$. As already demonstrated for Lupus Anticoagulant (28), the aPS/PT estimated risk is very close to that reported for deep vein thrombosis in patients with (72) and without (73) SLE. This risk has also been reported to be similar to and, in some instances, even higher than that in patients with genetically determined risk factors for venous thrombosis(74). 
Although the general population is unlikely to benefit from indiscriminate screening for these antibodies, their detection in patients with SLE, connective tissue diseases and/or previous thrombosis is justified by the high thrombotic risk associated with these clinical conditions. The aPT does not seem to be such a strong risk factor for APS, as less than $50 \%$ of their associations with thrombosis reached statistical significance. A sub-analysis of the different types of thrombosis showed that aPT are mainly associated with venous thrombosis although data available is vastly skewed. Whilst some data suggest that aPT antibodies are associated with thrombosis, a number of issues raise concern. Firstly, significant associations mainly come from retrospective studies, which contain a low level of evidence. Secondly, only a minority of studies confirm their findings by multivariate analysis. And finally, when the antibodies are analyzed in relation to the type of thrombosis, they are not associated with arterial events, and only marginally with thrombotic events as a whole. Overall, the potential role of aPT antibodies as laboratory tool for the diagnosis of APS still remains to be established. In this review we were unable to fully address the importance of antibody isotypes, as most studies investigated only IgG antibodies or did not distinguish between IgG and/or IgM. With these limitations, the association between IgM aPT and thrombosis is still elusive limiting their value in clinical practice. In contrast, our analysis strongly suggests that aPS/PT are associated with thrombosis. In this case, as well as per aPT, the fact that significant associations mainly came from retrospective studies, with a low level of evidence needs to be acknowledged. Intriguingly, despite a two-fold-increase in the risk for arterial thrombosis in aPS/PT positive, two recent studies failed in showing this association $(60,67)$. All in all, these findings need to be clearly substantiated by well-designed prospective clinical studies. The strengths of this analysis lie on a comprehensive search strategy, the inclusion of grey literature searches and manual review of reference lists minimized the risk of missing eligible studies. We performed independent and duplicate review for study selection, and data extraction. The use of the GRADE system and the NOS scale increases our confidence in our conclusions, and allows for reliable assessment of the quality of individual studies and the overall body of evidence. There are also limitations. All of the included studies were observational studies, subject to the biases inherent in this study design. The majority of the studies enrolled small numbers of patients, resulting in a loss of precision. Additionally, there was heterogeneity in the data. This resulted in the overall quality of the evidence being rated as "low," as per GRADE criteria.Overall, based on our data, routine measurement of aPS/PT might be useful in establishing the thrombotic risk of patients with previous thrombosis and/or SLE. In conclusion, aPS/PT and not aPT seem to be a potential candidate as a laboratory tool for the diagnosis of APS whereas their inclusion as laboratory criteria for the APS should be indisputably explored. Acknowledgements: MLB is funded by the Louise Gergel Fellowship. This work was supported by grants from the St Thomas' Lupus Trust.

Author Contributions

Study design. SS, MLB, GS, MK

Acquisition of data. SS, MLB, VM, DR

Analysis and interpretation of data. SS, MLB, GS, DR

Manuscript preparation. SS, MLB, GS, MK

Statistical analysis. SS, MLB 
References

1. Hughes GR. The antiphospholipid syndrome: ten years on. Lancet 1993 Aug 7;342(8867):341-4.

2. Miyakis S, Lockshin MD, Atsumi T, et al. International consensus statement on an update of the classification criteria for definite antiphospholipid syndrome (APS). Journal of thrombosis and haemostasis : JTH 2006 Feb;4(2):295-306.

3. A L. Prothrombin as a co-factor of the circulating anticoagulant in systemic lupus erythematosus? Thromb Diath Haemorrh 1959;3: 237-56.

4. Galli M, Barbui T. Antiprothrombin antibodies: detection and clinical significance in the antiphospholipid syndrome. Blood 1999 Apr 1;93(7):2149-57.

5. Haj-Yahia S, Sherer Y, Blank M, et al. Anti-prothrombin antibodies cause thrombosis in a novel qualitative exvivo animal model. Lupus 2003;12(5):364-9.

6. Bertolaccini ML, Atsumi T, Koike T, et al. Antiprothrombin antibodies detected in two different assay systems. Prevalence and clinical significance in systemic lupus erythematosus. Thrombosis and haemostasis 2005 Feb;93(2):289-97.

7. Bertolaccini ML, Gomez S, Pareja JF, et al. Antiphospholipid antibody tests: spreading the net. Annals of the rheumatic diseases 2005 Nov;64(11):1639-43.

8. Galli M, Luciani D, Bertolini G, et al. Anti-beta 2-glycoprotein I, antiprothrombin antibodies, and the risk of thrombosis in the antiphospholipid syndrome. Blood 2003 Oct 15;102(8):2717-23.

9. Galli M, Luciani D, Bertolini G, et al. Lupus anticoagulants are stronger risk factors for thrombosis than anticardiolipin antibodies in the antiphospholipid syndrome: a systematic review of the literature. Blood 2003 Mar 1;101(5):1827-32.

10. R L. Kappa as a Measure of Concordance in Categorical Sorting. http://facultyvassaredu/lowry/kappahtml Accessed May 28, 2013.

11. Wells GA SB, O'Connell D, Peterson J, Welch V, Losos M, Tugwell P. The NewcastleOttawa Scale (NOS) for assessing the quality of nonrandomised studies in meta-analyses.

http://wwwohrica/programs/clinical_epidemiology/oxfordasp Accessed May 28, 2013.

12. GRADE Working Group, GRADE profiler. GRADEpro Version. Available at: http://wwwgradeworkinggrouporg/ Accessed April 5, 2013.

13. Horbach DA, Derksen RH, de Groot PG. The presence of anti-beta 2-glycoprotein I and anti-prothrombin antibodies and their correlations with venous and arterial thrombosis. Annales de medecine interne 1996 Sep;147 Suppl 1:42-3.

14. Pengo V, Biasiolo A, Brocco T, et al. Autoantibodies to phospholipid-binding plasma proteins in patients with thrombosis and phospholipid-reactive antibodies. Thrombosis and haemostasis 1996 May;75(5):721-4.

15. Puurunen $\mathrm{M}$, Vaarala $\mathrm{O}$, Julkunen $\mathrm{H}$, et al. Antibodies to phospholipid-binding plasma proteins and occurrence of thrombosis in patients with systemic lupus erythematosus. Clinical immunology and immunopathology 1996 Jul;80(1):16-22. 
16. Forastiero RR, Martinuzzo ME, Cerrato GS, et al. Relationship of anti beta2- glycoprotein I and anti prothrombin antibodies to thrombosis and pregnancy loss in patients with antiphospholipid antibodies. Thrombosis and haemostasis 1997 Sep;78(3):1008-14.

17. Palosuo T, Virtamo J, Haukka J, et al. High antibody levels to prothrombin imply a risk of deep venous thrombosis and pulmonary embolism in middle-aged men--a nested casecontrol study. Thrombosis and haemostasis 1997 Oct;78(4):1178-82.

18. Bertolaccini ML, Atsumi T, Khamashta MA, et al. Autoantibodies to human prothrombin and clinical manifestations in 207 patients with systemic lupus erythematosus. The Journal of rheumatology 1998 Jun;25(6):1104-8.

19. Vaarala O. Antiphospholipid antibodies and myocardial infarction. Lupus 1998;7 Suppl 2:S132-4.

20. Martinuzzo ME, Pombo G, Forastiero RR, et al. Lupus anticoagulant, high levels of anticardiolipin, and antibeta2-glycoprotein I antibodies are associated with chronic thromboembolic pulmonary hypertension. The Journal of rheumatology $1998 \mathrm{Jul} ; 25(7): 1313-9$.

21. Akimoto T, Akama T, Kono I, et al. Relationship between clinical features and binding domains of antiprothrombin autoantibodies in patients with systemic lupus erythematosus and antiphospholipid syndrome. Lupus 1999;8(9):761-6.

22. Galli M, Dlott J, Norbis F, et al. Lupus anticoagulants and thrombosis: clinical association of different coagulation and immunologic tests. Thrombosis and haemostasis 2000 Dec;84(6):1012-6.

23. Lakos $\mathrm{G}$, Kiss E, Regeczy N, et al. Antiprothrombin and antiannexin $\mathrm{V}$ antibodies imply risk of thrombosis in patients with systemic autoimmune diseases. The Journal of rheumatology 2000 Apr;27(4):924-9.

24. Atsumi T, leko M, Bertolaccini ML, et al. Association of autoantibodies against the phosphatidylserineprothrombin complex with manifestations of the antiphospholipid syndrome and with the presence of lupus anticoagulant. Arthritis and rheumatism 2000 Sep;43(9):1982-93.

25. Donohoe S, MacKie IJ, Isenberg D, et al. Anti-prothrombin antibodies: assay conditions and clinical associations in the anti-phospholipid syndrome. British journal of haematology 2001 May;113(2):544-9.

26. Nojima J, Kuratsune $H$, Suehisa E, et al. Anti-prothrombin antibodies combined with lupus anti-coagulant activity is an essential risk factor for venous thromboembolism in patients with systemic lupus erythematosus. British journal of haematology 2001 Sep;114(3):647-54.

27. Nojima J, Kuratsune $H$, Suehisa E, et al. Association between the prevalence of antibodies to beta(2)glycoprotein I, prothrombin, protein $\mathrm{C}$, protein $\mathrm{S}$, and annexin $\mathrm{V}$ in patients with systemic lupus erythematosus and thrombotic and thrombocytopenic complications. Clinical chemistry 2001 Jun;47(6):1008-15.

28. Pasquier E, Amiral J, de Saint Martin L, et al. A cross sectional study of antiphospholipid-protein antibodies in patients with venous thromboembolism. Thrombosis and haemostasis 2001 Aug;86(2):538-42.

29. Sands JJ, Nudo SA, Moore KD, et al. Antibodies to prothrombin, factor V, and beta2-glycoprotein I and vascular access thrombosis. ASAIO J 2001 Sep-Oct;47(5):507-10.

30. Donohoe S. Detection and clinical associations of antiprothrombin antibodies. The American journal of medicine 2001 Feb 15;110(3):229-30. 
31. Salcido-Ochoa F, Cabiedes J, Alarcon-Segovia D, et al. Antiprothrombin antibodies in patients with systemic lupus erythematosus or with primary antiphospholipid syndrome. Journal of clinical rheumatology : practical reports on rheumatic \& musculoskeletal diseases 2002 Oct;8(5):251-5.

32. Simmelink MJ, De Groot PG, Derksen RH. A study on associations between antiprothrombin antibodies, antiplasminogen antibodies and thrombosis. Journal of thrombosis and haemostasis : JTH 2003 Apr;1(4):735-9.

33. Previtali S, Barbui T, Galli M. Anti-beta2-glycoprotein I and anti-prothrombin antibodies in antiphospholipidnegative patients with thrombosis: a case control study. Thrombosis and haemostasis 2002 Nov;88(5):729-32.

34. Musial J, Swadzba J, Motyl A, et al. Clinical significance of antiphospholipid protein antibodies. Receiver operating characteristics plot analysis. The Journal of rheumatology 2003 Apr;30(4):723-30.

35. Ishikura K, Wada H, Kamikura $\mathrm{Y}$, et al. High prevalence of anti-prothrombin antibody in patients with deep vein thrombosis. American journal of hematology 2004 Aug;76(4):338- 42.

36. Koskenmies S, Vaarala O, Widen E, et al. The association of antibodies to cardiolipin, beta 2-glycoprotein I, prothrombin, and oxidized low-density lipoprotein with thrombosis in 292 patients with familial and sporadic systemic lupus erythematosus. Scandinavian journal of rheumatology 2004;33(4):246-52.

37. Zanon E, Saggiorato G, Ramon R, et al. Anti-prothrombin antibodies as a potential risk factor of recurrent venous thromboembolism. Thrombosis and haemostasis 2004 Feb;91(2):255-8.

38. Forastiero R, Martinuzzo M, Pombo G, et al. A prospective study of antibodies to beta2-glycoprotein I and prothrombin, and risk of thrombosis. Journal of thrombosis and haemostasis : JTH 2005 Jun;3(6):1231-8

39. Tsutsumi A, Hayashi T, Chino Y, et al. Significance of antiprothrombin antibodies in patients with systemic lupus erythematosus: clinical evaluation of the antiprothrombin assay and the antiphosphatidylserine/prothrombin assay, and comparison with other antiphospholipid antibody assays. Modern rheumatology / the Japan Rheumatism Association 2006;16(3):158-64.

40. Gould T, Tikly M, Asherson R, et al. Prevalence and clinical correlates of antiphospholipid antibodies in South Africans with systemic lupus erythematosus. Scandinavian journal of rheumatology 2006 Jan-Feb;35(1):29-34.

41. Bizzaro N, Ghirardello A, Zampieri S, et al. Anti-prothrombin antibodies predict thrombosis in patients with systemic lupus erythematosus: a 15-year longitudinal study. Journal of thrombosis and haemostasis : JTH 2007 Jun;5(6):1158-64.

42. Sailer T, Vormittag R, Zoghlami C, et al. The clinical significance of anti-prothrombin antibodies for risk assessment of thromboembolism in patients with lupus anticoagulant. Thrombosis research 2007;120(2):295-302.

43. Bardin N, Alessi MC, Dignat-George F, et al. Does the anti-prothrombin antibodies measurement provide additional information in patients with thrombosis? Immunobiology 2007;212(7):557-65.

44. Szodoray P, Tarr T, Tumpek J, et al. Identification of rare anti-phospholipid/protein co-factor autoantibodies in patients with systemic lupus erythematosus. Autoimmunity 2009 Sep;42(6):497-506.

45. Rask O, Hillarp A, Berntorp E, et al. Anti-prothrombin antibodies are associated with thrombosis in children. Thrombosis research 2010 Jan;125(1):19-24. 
46. Hoxha A, Ruffatti A, Pittoni M, et al. The clinical significance of autoantibodies directed against prothrombin in primary antiphospholipid syndrome. Clinica chimica acta; international journal of clinical chemistry 2012 May 18;413(9-10):911-3.

47. Horita $\mathrm{T}$, Ichikawa $\mathrm{K}$, Kataoka $\mathrm{H}$, et al. Human monoclonal antibodies against the complex of phosphatidylserine and prothrombin from patients with the antiphospholipid antibodies. Lupus 2007;16(7):50916.

48. Jaskowski TD, Wilson AR, Hill HR, et al. Autoantibodies against phosphatidylserine, prothrombin and phosphatidylserine-prothrombin complex: identical or distinct diagnostic tools for antiphospholipid syndrome? Clinica chimica acta; international journal of clinical chemistry 2009 Dec;410(1-2):19-24.

49. Locht $H$, Wiik A. Prevalence of antibodies against oxidised LDL in a cohort of 163 patients with positive antiphospholipid antibodies and recent thrombosis. Rheumatology international 2006 Mar;26(5):416-21.

50. Miesbach W, Matthias T, Scharrer I. Identification of thrombin antibodies in patients with antiphospholipid syndrome. Annals of the New York Academy of Sciences 2005 Jun;1050:250-6.

51. Horbach DA, van Oort E, Tempelman MJ, et al. The prevalence of a nonphospholipid-binding form of beta2glycoprotein I in human plasma--consequences for the development of anti-beta2-glycoprotein I antibodies. Thrombosis and haemostasis 1998 Nov;80(5):791-7.

52. Nojima J, Iwatani Y, Suehisa E, et al. The presence of antiphosphatidylserine/prothrombin antibodies as risk factor for both arterial and venous thrombosis in patients with systemic lupus erythematosus. Haematologica 2006 May;91(5):699-702.

53. Adams MJ, Palatinus AA, Harvey AM, et al. Impaired control of the tissue factor pathway of blood coagulation in systemic lupus erythematosus. Lupus 2011 Dec;20(14):1474-83.

54. Lee KO, Kim WJ, Na SJ, et al. Clinical significance of anti-annexin V antibody in acute cerebral ischemia. Journal of the neurological sciences 2011 Jun 15;305(1-2):53-6.

55. Cojocaru IM, Cojocaru M, Popescu AN, et al. Study of antiphospholipid antibodies in type 2 diabetes mellitus with and without diabetic retinopathy. Romanian journal of internal medicine $=$ Revue roumaine de medecine interne 2009;47(3):267-71.

56. Robertson B, Urquhart C, Ford I, et al. Platelet and coagulation activation markers in myeloproliferative diseases: relationships with JAK2 V617 F status, clonality, and antiphospholipid antibodies. Journal of thrombosis and haemostasis : JTH 2007 Aug;5(8):1679-85.

57. Santamaria A, Oliver A, Borrell $M$, et al. Risk of ischemic stroke associated with functional thrombinactivatable fibrinolysis inhibitor plasma levels. Stroke; a journal of cerebral circulation 2003 Oct;34(10):2387-91.

58. Chen WH, Kao YF, Lan MY, et al. A perturbation of antithrombin-III and protein C coupling associates with an increase of anti-beta2-glycoprotein I antibody in nonantiphospholipid antibody syndrome cerebral ischemia.

Blood coagulation \& fibrinolysis : an international journal in haemostasis and thrombosis 2002 Dec;13(8):703-9.

59. Adams MJ, Donohoe S, Mackie IJ, et al. Anti-tissue factor pathway inhibitor activity in patients with primary antiphospholipid syndrome. British journal of haematology 2001 Aug;114(2):375-9. 
60. Hoxha A, Ruffatti A, Tonello M, et al. Antiphosphatidylserine/prothrombin antibodies in primary antiphospholipid syndrome. Lupus 2012 Jun;21(7):787-9.

61. Okuma H, Kitagawa $\mathrm{Y}$, Ishikawa $\mathrm{T}$, et al. Study of phosphatidylserine-dependent antiprothrombin antibody in cerebral infarction. Intern Med 2009;48(16):1351-5.

62. Bertolaccini ML, Atsumi T, Escudero Contreras A, et al. The value of IgA antiphospholipid testing for diagnosis of antiphospholipid (Hughes) syndrome in systemic lupus erythematosus. The Journal of rheumatology 2001 Dec;28(12):2637-43.

63. Hasegawa M, Sato S, Yanaba K, et al. Autoantibodies against phosphatidylserineprothrombin complex in patients with systemic sclerosis. Annals of the rheumatic diseases 2004 Nov;63(11):1514-7.

64. Hasegawa M, Fujimoto M, Hayakawa I, et al. Anti-phosphatidylserine-prothrombin complex antibodies in patients with localized scleroderma. Clinical and experimental rheumatology 2006 Jan-Feb;24(1):19-24.

65. Nojima J, Kuratsune $\mathrm{H}$, Suehisa $\mathrm{E}$, et al. Acquired activated protein $\mathrm{C}$ resistance associated with IgG antibodies against beta2-glycoprotein I and prothrombin as a strong risk factor for venous thromboembolism. Clinical chemistry 2005 Mar;51(3):545-52.

66. Nojima J, Kuratsune $H$, Suehisa $E$, et al. Strong correlation between the prevalence of cerebral infarction and the presence of anti-cardiolipin/beta2-glycoprotein I and antiphosphatidylserine/prothrombin antibodies--Coexistence of these antibodies enhances 26 ADP-induced platelet activation in vitro. Thrombosis and haemostasis 2004 May;91(5):967- 76.

67. Vlagea AD, Gil A, Cuesta MV, et al. Antiphosphatidylserine/Prothrombin Antibodies (aPS/PT) as Potential Markers of Antiphospholipid Syndrome. Clinical and applied thrombosis/hemostasis : official journal of the International Academy of Clinical and Applied Thrombosis/Hemostasis 2012 Mar 2.

68. Inanc M, Donohoe S, Ravirajan CT, et al. Anti-beta2-glycoprotein I, anti-prothrombin and anticardiolipin antibodies in a longitudinal study of patients with systemic lupus erythematosus and the antiphospholipid syndrome. British journal of rheumatology 1998 Oct;37(10):1089-94.

69. Zigon P, Ambrozic A, Cucnik S, et al. Modified phosphatidylserine-dependent antiprothrombin [corrected] ELISA enables identification of patients negative for other antiphospholipid antibodies and also detects low avidity antibodies. Clinical chemistry and laboratory medicine : CCLM / FESCC 2011 Jun;49(6):1011-8.

70. Zigon P, Cucnik S, Ambrozic A, et al. Antibodies to phosphatidylserine/prothrombin complex as an additional diagnostic marker of APS? Lupus 2012 Jun;21(7):790-2.

71. Pengo V, Denas G, Bison E, et al. Prevalence and significance of anti-prothrombin (aPT) antibodies in patients with Lupus Anticoagulant (LA). Thrombosis research 2010 Aug;126(2):150-3.

72. Wahl DG, Guillemin F, de Maistre E, et al. Risk for venous thrombosis related to antiphospholipid antibodies in systemic lupus erythematosus--a meta-analysis. Lupus 1997;6(5):467-73.

73. Wahl DG, Guillemin F, de Maistre E, et al. Meta-analysis of the risk of venous thrombosis in individuals with antiphospholipid antibodies without underlying autoimmune disease or previous thrombosis. Lupus 1998;7(1):1522. 
74. Martinelli I, Mannucci PM, De Stefano V, et al. Different risks of thrombosis in four coagulation defects associated with inherited thrombophilia: a study of 150 families. Blood 1998 Oct 1;92(7):2353-8.

Table 1: aPT and thrombosis: main characteristics of 38 articles on 5705 patients and 1262 controls

\begin{tabular}{|c|c|c|c|c|c|}
\hline Article and Ref Number & Year & Study design & N.patients and Enrolment criteria & N. Controls & Isotypes \\
\hline Horbach et al (9) & 1996 & $\mathrm{R}(\mathrm{M})$ & 175 SLE & 23 thrombosis, 40 aPL carriers, $42 \mathrm{HC}$ & IgG/IGM \\
\hline Pengo et al (10) & 1996 & $\mathbf{R}$ & 22 APS & & $\lg G$ \\
\hline Puurunen et al (11) & 1996 & $\mathbf{R}$ & 139 APS & & IgG/IGM \\
\hline Forastiero et al (12) & 1997 & $\mathrm{R}(\mathrm{M})$ & 233 aPL positive & & IgG/IGM \\
\hline Palosuo et al (13) & 1997 & CS & 265 DVT & $265 \mathrm{HC}$ & IgG \\
\hline Bertolaccini et al (14) & 1998 & $\mathbf{R}$ & 207 SLE & & IgG/IGM \\
\hline Vaarala et al (15) & 1998 & CS & 106 IMA & 106 coronary episodes & $\lg \mathrm{G}$ \\
\hline Martinuzzo et al (16) & 1998 & $\mathbf{R}$ & 54 pulmonary hypertension & & $\mathrm{IgG} / \mathrm{M}$ \\
\hline Akimoto et al (17) & 1999 & $R(M)$ & 13 aPL positive & & IgG/IGM \\
\hline Galli et al (18) & 2000 & $\mathbf{R}$ & 75 aPL positive & & IgG/IGM \\
\hline Lakos et al (19) & 2000 & $\mathbf{R}$ & $70 \mathrm{SLE}$ & & IgG/IGM \\
\hline Atsumi et al (20) & 2000 & $\mathrm{R}(\mathrm{M})$ & 265 SLE & $36 \mathrm{HC}$ & IgG/IGM \\
\hline Donohoe et al (21) & 2001 & $\mathbf{R}$ & 66 APS & $30 \mathrm{HC}, 42$ SLE & IgG/IGM \\
\hline Nojima et al (22) & 2001 & $\mathrm{R}(\mathrm{M})$ & 124 SLE & & IgG/IGM \\
\hline Nojima et al (23) & 2001 & $\mathrm{R}(\mathrm{M})$ & 168 SLE & $80 \mathrm{HC}$ & IgG/IGM \\
\hline Pasquier et al (24) & 2001 & CS & 398 suspected VTE & & IgG/IGM \\
\hline Sands et al (25) & 2001 & $\mathbf{R}$ & 88 haemodialysis & & IgG/IGM \\
\hline Salcido-Ochoa et al (27) & 2002 & $\mathbf{R}$ & 38 PAPS, 466 SLE & & $\operatorname{lgG} /$ IGM \\
\hline Simmelink et al (28) & 2003 & $\mathbf{R}$ & 46 SLE & $40 \mathrm{HC}$ & IgG/IGM \\
\hline Previtali et al (29) & 2002 & $\mathrm{CC}$ & 79 arterial/venous thrombosis & $85 \mathrm{HC}$ & $\operatorname{lgG} / \mathrm{M}$ \\
\hline Musial et al (30) & 2003 & $\mathbf{R}$ & 160 SLE, 22 Lupus-Like, 22 APS & & IgG/IGM \\
\hline Ishikura et al (31) & 2004 & $\mathbf{R}$ & $78 \mathrm{DVT} /$ cerebral thrombosis & $22 \mathrm{SLE}, 30 \mathrm{ITP}, 40 \mathrm{HC}$ & IgG/IGM \\
\hline Koskenmies et al (32) & 2004 & $\mathbf{R}$ & 292 SLE & & IgG/IGM \\
\hline Zanon et al (33) & 2004(M) & $\mathbf{R}$ & 236 DVT & & $\lg G / M$ \\
\hline Forastiero et al (34) & 2005(M) & $\mathbf{P}$ & 194 aPL positive & & IgG/IGM \\
\hline Bertolaccini et al (5) & 2005 & $\mathbf{R}$ & 212 SLE & $100 \mathrm{HC}$ & $\operatorname{lgG} / \mathrm{IGM}$ \\
\hline Bertolaccini et al (6) & 2005 & $\mathbf{R}$ & 168 SLE & & IgG/IGM \\
\hline Tsutsumi et al (35) & 2006 & $\mathbf{R}$ & 139 SLE & & IgG/IGM \\
\hline Gould et al (36) & 2006 & CS & 100 SLE & & IgG/IGM/IgA \\
\hline Bizzarro et al (37) & 2006 & $\mathrm{P}(\mathrm{M})$ & 101 SLE & & IgG \\
\hline Sailer et al (38) & 2007 & $\mathrm{R}(\mathrm{M})$ & 79 LA positive & & $\operatorname{lgG} / \mathrm{M}$ \\
\hline Bardin et al (39) & 2007 & $\mathbf{R}$ & 152 thrombosis & $120 \mathrm{HC}$ & IgG \\
\hline Szodoray et al (40) & 2009 & $\mathbf{R}$ & 85 SLE & & IgG/IgM \\
\hline Rask et al (41) & 2010 & $\mathbf{R}$ & 57 acute thrombosis & $47 \mathrm{HC}$ & IgG/IGM \\
\hline Pengo et al (65) & 2010 & $\mathbf{R}$ & 231 LA positive & & IgG/IGM \\
\hline Hoxha et al (42) & 2012 & $\mathbf{R}$ & 158 PAPS & $100 \mathrm{HC}, 114$ autoimmune conditions & IgG/IGM \\
\hline
\end{tabular}

SLE: systemic lupus erythematosus; APS: antiphospholipid syndrome; HC: healthy controls; aPL: antiphospholipid antibodies; DVT: deep vein thrombosis;

IMA: ischemic myocardial attack; PAPS: Primary antiphospholipid syndrome; LA: lupus anticoagulant; VTE: venous thrombo- embolism; HCV: hepatitis C

virus

R: retrospective study; CS: cross-sectional study; CC: case-control study; L: longitudinal study; M: multivariate analysis 
Table 2: aPS/PT and thrombosis: main characteristics of 10 articles on 1775 patients and 628 controls

\begin{tabular}{|c|c|c|c|c|c|}
\hline Article and Ref Number & Year & Study design & $\begin{array}{l}\mathrm{N} \text { patients } \\
\text { and Enrolment criteria }\end{array}$ & N. Controls & Isotypes \\
\hline Atsumi et al (20) & 2000 & $\mathrm{R}(\mathrm{M})$ & 265 SLE & & $\operatorname{lgG} / \mathrm{IGM}$ \\
\hline Nojima et al (62) & 2004 & $\mathrm{R}(\mathrm{M})$ & 126 SLE & $80 \mathrm{HC}$ & IgG \\
\hline Bertolaccini et al (5) & 2005 & $\mathbf{R}$ & 212 SLE & $100 \mathrm{HC}$ & $\operatorname{IgG/IGM}$ \\
\hline Bertolaccini et al (6) & 2005 & $\mathbf{R}$ & 168 SLE & & IgG/IGM \\
\hline Tsutsumi et al (35) & 2006 & $\mathbf{R}$ & 139 SLE & $148 \mathrm{HC}$ & IgG/IGM \\
\hline Nojima et al (48) & 2006 & $\mathrm{R}(\mathrm{M})$ & 175 SLE & $80 \mathrm{HC}$ & IgG \\
\hline Bardin et al (39) & 2007 & $\mathbf{R}$ & 152 pts with thrombosis & $120 \mathrm{HC}$ & IgG \\
\hline Szodoray et al (40) & 2009 & $\mathbf{R}$ & 85 SLE & & $\lg G / \lg M$ \\
\hline Hoxha et al (42) & 2012 & $\mathrm{R}(\mathrm{M})$ & 158 PAPS & $100 \mathrm{HC}$ & IgG/IGM \\
\hline Vlagea et al (63) & 2012 & $\mathrm{R}(\mathrm{M})$ & $\begin{array}{l}295 \text { suspected APS or Autoimmune } \\
\text { disease }\end{array}$ & & IgG/IGM \\
\hline
\end{tabular}

SLE: systemic lupus erythematosus, APS: antiphospholipid syndrome, HC: healthy controls, PAPS: Primary antiphospholipid syndrome; $R$ : retrospective study; M: multivariate analysis 